\title{
Superficial Galactocelic Progression, Size-Variation and Assessment in a Patient
}

\author{
Adam Moyosore Afodun ${ }^{1,2^{*}}$, Khadijah Kofoworola Quadri ${ }^{3}$, Mustapha Akajewole Masud ${ }^{4}$, \\ Adigun Musibau Hammed ${ }^{5}$
}

\footnotetext{
${ }^{1}$ Department of Anatomy, School of Biomedical Sciences, Kampala International University, Western Campus, Ishaka, Uganda ${ }^{2}$ Department of Radiology, Ultrasound and Doppler Unit, Crystal Specialist Hospital, Lagos, Nigeria

${ }^{3}$ Department of Physiology, College of Medicine, University of Lagos, Lagos, Nigeria

${ }^{4}$ Department of Anatomy, State University of Zanzibar, Zanzibar, Tanzania

${ }^{5}$ Department of Anatomy, Faculty of Basic Medical Sciences, University of Ilorin, Ilorin, Nigeria

Email: *afodunadam@yahoo.com
}

How to cite this paper: Afodun, A.M., Quadri, K.K., Masud, M.A. and Hammed, A.M. (2017) Superficial Galactocelic Progression, Size-Variation and Assessment in a Patient. Advances in Breast Cancer Research, 6, 100-106.

https://doi.org/10.4236/abcr.2017.64009

Received: July 18, 2017

Accepted: September 17, 2017

Published: September 20, 2017

Copyright (c) 2017 by authors and Scientific Research Publishing Inc. This work is licensed under the Creative Commons Attribution International License (CC BY 4.0).

http://creativecommons.org/licenses/by/4.0/

\begin{abstract}
Breast cysts (galactocele) form in the mammary gland from ductal obstruction. Multiple pathologic entities may produce complex cystic breast lesions. Ultrasound is presently the first primary modality in breast evaluation after physical palpitation. We report a progressive case of multiple cysts in a 32 -year-old woman, ranging from $28 \mathrm{~mm}$ to $20 \mathrm{~mm}$. Though in-situ milk (sono-penic) appears sterile, the superficial presentation (externally) is that of a firm mass. Due to the known hazards of radioactive mammography, this case report proves the usefulness of sonar to image, map, measure, identify and diagnose breast pathology. In women with dense-heavy breast, ultrasound examination will play an important role in screening palpable and non-palpable masses.
\end{abstract}

\section{Keywords}

Galactocele, Cysts, Mass, Breast

\section{Introduction}

A galactocele is a cyst that forms from the obstruction of a lactiferous duct within the breast. Galactocele appear similar to simple cysts but instead contain milk, they can mimic or have parallel features to fibro-adenoma, carcinoma and other breast lesions [1]. A galactocele is the most ubiquitous benign mass lesion diagnosed during lactation it may develop after stoppage of breastfeeding or neonate suckling when milk is stagnant [2]. 
Breast cysts developing in the bilateral mammary glands are known as galactocele. Ultrasound is presently the first primary modality in breast examination after physical palpitation. Cysts are simple or complex, may contain solid components associated with its atypical nature or be of a variety related to malignant pathology [3]. Complex breast cysts are distinct from galactocele in that they possess thick septa walls, have other discrete solid components or intra-cystic masses [3]. Complex cysts of the mammary glands are sometimes separated, with thick-walls and with intra-cystic masses in-situ.

Fibrocystic changes are sometimes inclusive of sclerosing adenosis, ductal ectasis and lateral apocrine metaplasia [4]. Fatty and necrotic tissue from surgery (or traumatic history), as well as galactocele may occur and morph into giant complex cystic lesions. Aspiration of a galactocele is both therapeutic and diagnostic, clinically when palpating; a galactocele appears as a well circumscribed roundish mass that is often mobile [5]. Breast cysts form in preparation for lactation, since pregnancy is a unique physiologic time frame where higher circulating levels of hormones, ductal growth, reduction in stroma and increased vascularity precipitate breast tissue [6]. Irrespective of cystic size, lymph nodes that drain the breast are in the axilla, enmeshed in a network of ducts and lobes [7] [8]. Galactocele are the most common benign breast lesions in lactating women [5] while its location in the axillary part of accessory breast is a rare occurrence [9]. Galactocele can be associated with necrosis and inflammation [2]. However, if a galactocelic lesion is seen during early gravidae before parturition, a biopsy may be considered [10].

\section{Objective}

The purpose of this case report is to evaluate sonographic appearance of a galactocele that mimics a suspicious solid mass, and to differentiate between this galactocelic case note and similar solid breast mass.

\section{Case Report}

A 32-year old woman with a feeling of heaviness in the left breast presented to a physician; before ultrasound referral. No oral pain or complaint on palpitation at 11 O'clock position (para-areola region); mid-clavicular line. Ultrasound scan was performed using a $7-10 \mathrm{MH}_{\mathrm{z}}$ linear-array transducer on a Logic 3 Pro, General Electric (GE) equipment at Crystal Specialist Hospital (CSH); DopemuAkowonjo-Lagos.

Our judgement on galactocelic ultrasound appearance also depends on the micro-cystic amount of water and fat contents. Since galactocele with "old milk" and proteinaceous substances may present with pseudo-solid appearance with hypoechoic reverberations. At the time of ultrasound ( 3 months post-natal) patient had been lactating and none of the galactocele appeared infected. On (oral) sonologist interaction with subject, no family history of breast lumps was declared. 
Scan focused on cysts (Figure 1 and Figure 2), enabled (encompassing) kinetic enhancement with proper gain adjustment. Ultrasound showed multiple, oval-circumscribed (BI-RADS scale); anechoic structure: $29 \mathrm{~mm} \times 18 \mathrm{~mm}$ in average diameter, with faint posterior acoustic enhancement. Additional diagnostic investigations were not indicated in the mother and she was reassured

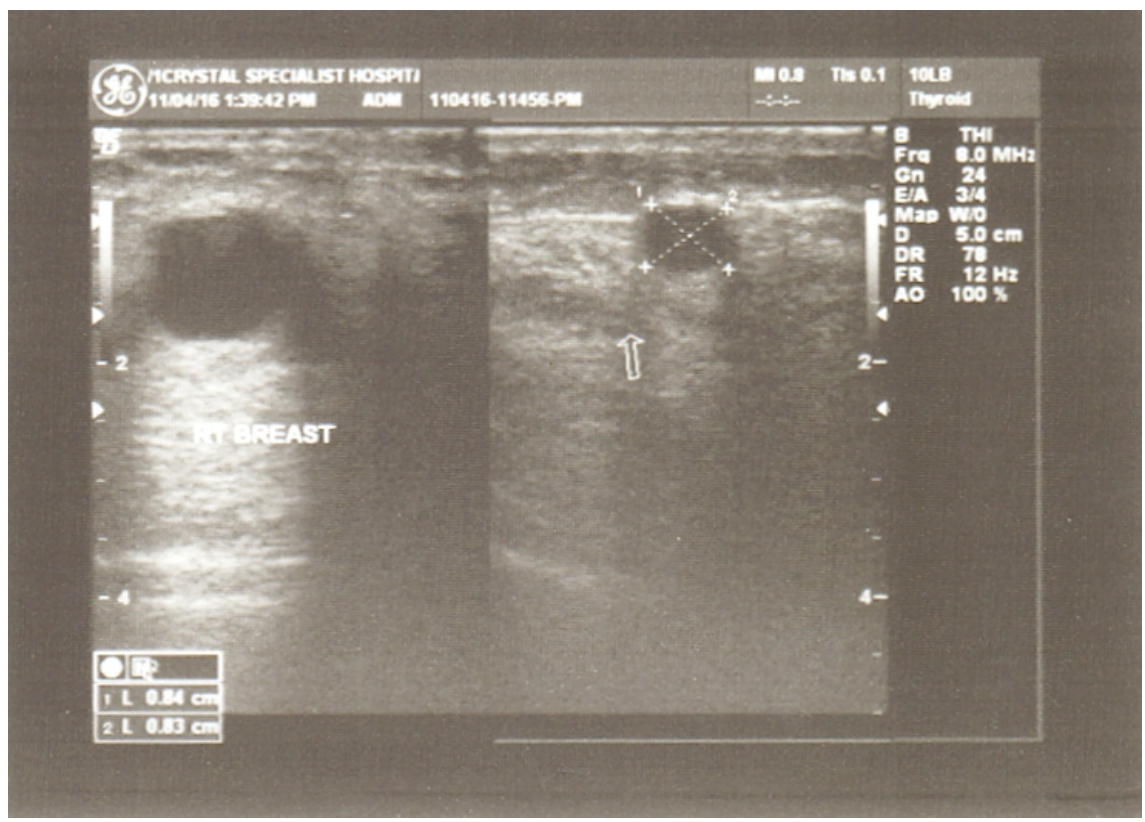

Figure 1. Gray scale transverse section of anechoic masses with dimension $\mathrm{L} \times \mathrm{B}(28 \mathrm{~mm}$ $\times 20 \mathrm{~mm}$ ) and a $18 \mathrm{~mm}$ cyst respectively. Follow-up on cyst resolved after some months and yielded no blood. Note the posterior enhancement.

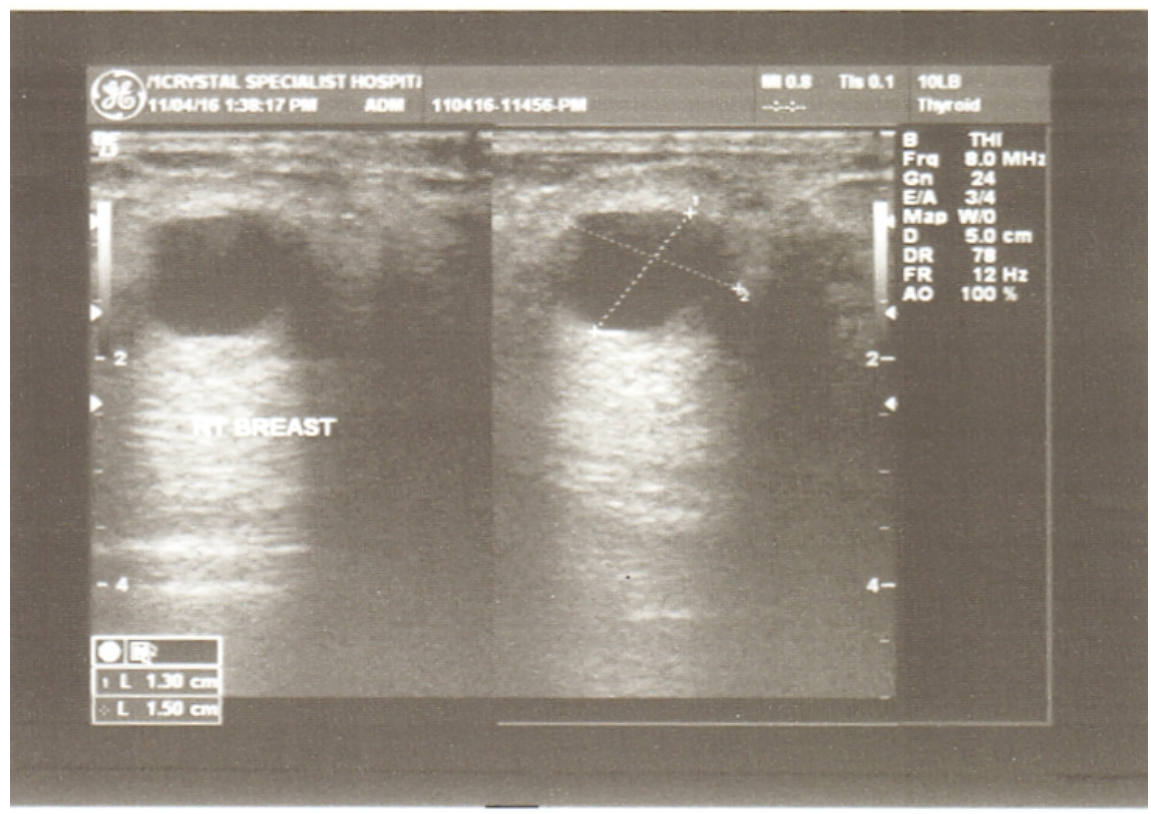

Figure 2. Sonogram in (radial) supra-areola region (11 o'clock) showing heterogeneous tissue surrounding mass $28 \mathrm{~mm}$ in length. No evidence of dependent intra-cystic echoes seen, a type II mass. Surrounding tissue free of any adjunct vascularity/anastomosis. 
to have a follow-up ultrasound after 90 days. No evidence of breast proliferative changes or "peau-de-orange" sign was seen on physical examination. We report a case of multiple galactoceles in the breast tissue of the mammary gland masquerading a suspicious mass. As a sonologist who is familiar with breast anatomy; the gray-scale knob was adjusted to a shade of moderate gray avoiding the black background.

Case note showed no evidence of any (hereditary) thoracic disease. The palpable mass $(2.9 \mathrm{~cm})$ was a source of great anxiety for the woman and her immediate family.

Cytological examination was negative for malignant cells. No coercion or inducement was given, in line with the 1965 Helsinki Declaration on patients' right. Hospital Ethical Review Committee approved the documentation of this case report. Informed consent of the patient was sought in full confidentiality and language she understood. The objective aims of the case report contributes sparse beneficial knowledge to the body of clinical medical literature.

\section{Discussion}

In rare instance when galactocele appears as a solid tumor, fibroadenoma and invasive carcinoma should be considered [11]. According to literature; the Breast Imaging Reporting and Data System (BI-RADS); galactocele accounts for estimated 5\% of breast complaints [5]. Accordingly, [12] 4 classes of complex breast cysts exist (Types I, II, III and IV) depending on outer wall thickness, presence of intra-cystic masses, solid components or eccentric central foci. As presented in the Figure 1 and Figure 2 galactoceles if accurately diagnosed are not serious or dangerous but mainly associated with psychological worry and maternal discomfort. Our finding in this case report is in agreement with [1]; postulating other factors for galactocelic occurrence are breast ductal obstruction, oral contraceptives, previous or present prolactin stimulation with a discontinued internal secretory breast epithelium. The breast retromammary space (of Spence) appeared "clear", adistinction from other types of fibrocystic breasts and pathologic fibro-adenoma. Fibro-glandular tissue become more prominent (through ultrasound) compared to X-rays (Figure 1 and Figure 2).

Delay in galactocelic diagnosis can be relayed to hypertrophy of breast tissue during breast-feeding (lactation) and pregnancy (gravidae) which can spike symptoms [13]. Breast x-ray (mammography) in lactating women often shows dense breast tissue, hence the emphasis on ultrasound as a preferred imaging choice which carries no risk of fetal radiation [14].

In the "near-gain" knobologic field (Figure 2), posterior acoustic enhancement and mass echo patterns are often associated with grand breast lesions [15]; [8]. As seen in Figure 2 for confirmation of breast galactocele, ventral or dorsal echogenic rim should be exhibited by this cyst (classified as a type II), note the posterior acoustic shadowing. A follow up period of 60 days interval between both scan session was given. Lateral echoes may be present in galactoceles, how- 
ever its genesis remain milky and fatty liquids associated with lactating women. Ultrasound examination of the left breast did not reveal lymphadenopathy. Considering the patient was in breastfeeding period our first diagnosis was a galactocele in the (lateral) upper quadrant of the breast tissue, but because the sonar appearance (Figure 2) is consistent with the ultrasound criteria of a benign simple cysts. Our observation is in line with [16] who described internal echo material exhibiting rigid well-designed echogenic walls. It should be emphasised that since galactocele has a wide range of sonographic appearance, diagnostic clues include; recent childbirth and lactation. In a confirmatory histo-pathological tissue sample, results collaborated diagnosis by ultrasound.

In agreement with [17], ductal dilation occurs due tosimple cysts; thereby making abscesses and rigid mastitis common due to "static" milk (non-flowing). Marked proximity of ducts in this region (posterior to areola) galactocele formation is likely [8] [18]. Another justification for galactocelic examination with ultrasound is that the mammography of breastfeeding women is usually very dense and difficult to interpret irrespective of cystic presence or not [19]. These non-proliferative findings in this (breast cyst-case report) are not associated with carcinoma of the mammary glands, thus making it (galactocele) distinct from other breast masses with well circumscribed walls. Breast X-ray and thermographic exposure, will produce obvious hyper-echogenicity and minimal reverberating artefactsas indicated in galactocele report [1]. As confirmed by sonography (Figure 2 and Figure 3), and since it is non-malignant we did not suggest mammography. On ultrasound, galactocele often appears as an hypoechoic lesion with well-rounded/circumscribed border that is parallel (wider-than-tall) in shape. Note the demonstration of both anechoic (cystic) and echoic (solid) components in the sonogram (Figure 2 and Figure 3). In lactating and non-breast

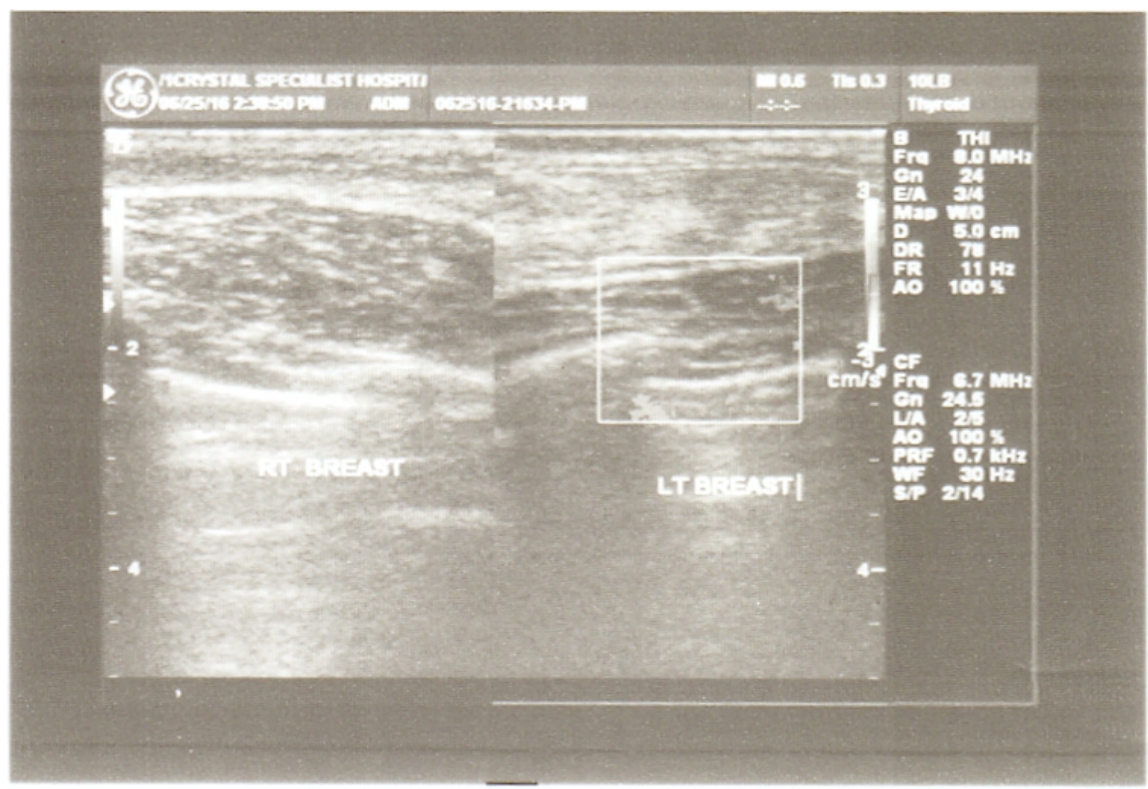

Figure 3. Normal left (Control) breast parenchymal tissue with uniform (homogenous) fibrous tissue and retinacula cutis. 
feeding women, sonography is a beneficial tool assisting sonologistsin diagnosis of general breast lesions. In conclusion, (invasive) real-time ultrasound-guided needle aspiration on cysts can be performed for further cytopathologic investigations.

\section{Conclusion}

Palpable breast masses are always a cause for worry and results in great anxiety for the breastfeeding or gravid patient. Therefore, knowledge-of-management and differential potential diagnoses are essential for physicians dealing with mammary gland lump progressions in women.

\section{References}

[1] Kim, M.J., Kim, E.K., Park, S.Y. and Jung, H.K. (2006) Galactoceles Mimicking Suspicious Solid Masses on Sonography. Journal of Ultrasound in Medicine, 25, 145 151. https://doi.org/10.7863/jum.2006.25.2.145

[2] Sabate, J.M., Clotet, M., Torrubia, S., Gomez, A., Guerrero, R., de las Heras, P. and Lerma, E. (2007) Radiologic Evaluation of Breast Disorders Related to Pregnancy and Lactation. Radiographics, 27, S101-S124. https://doi.org/10.1148/rg.27si075505

[3] American College of Radiology (2003) ACR-BI-RADS-Ultrasound. In: ACR Breast Imaging Reporting and Data System, Breast Imaging Atlas. American College of Radiology, Reston.

[4] Schnitt, S.J. and Connolly, J.L. (2004) Pathology of Benign Breast Disorders. In: Harris, J.R., Lippman, M.E., Morrow, M. and Osborne, C.K., Eds., Diseases of the Breast, 3rd Edition, Lippincott, Williams \& Wilkins, Philadelphia, 77-100.

[5] Whang, I.Y., Lee, J. and Kim, K.T. (2007) Galactocele as a Changing Axillary Lump in a Pregnant Woman. Archives of Gynecology and Obstetrics, 276, 379-382. https://doi.org/10.1007/s00404-007-0348-y

[6] Robbins, J., Jefferies, D., Roubidoux, M. and Helvie, M. (2011) Accuracy of Diagnostic Mammography and Breast Ultrasound during Pregnancy and Lactation. American Journal of Roentgenology, 196, 716-722. https://doi.org/10.2214/AJR.09.3662

[7] Hagan-Ansert, S. (2012) The Breast. In: Hagan-Ansert, S., Ed., Textbook of Diagnostic Sonography, 7th Edition, Elsevier, St. Louis, 549-587.

[8] Cottrell, M.R. and Fisher, K.L. (2016) Variation in Galactocele Location and Sonographic Appearance. Journal of Diagnostic Medical Sonography, 32, 24-227. https://doi.org/10.1177/8756479316652480

[9] Hall, I.M. (1986) Galactocele: Three Distinctive Radiographic Appearances. Radiology, 160, 852-853. https://doi.org/10.1148/radiology.160.3.3737931

[10] Schackmuth, E.M., Harlow, C.L. and Norton, L.W. (1993) Milk Fistula: A Complication after Core Breast Biopsy. American Journal of Roentgenology, 161, 961-962. https://doi.org/10.2214/ajr.161.5.8273635

[11] Goyal, S., Puri, R., Gupta, P. and Rath, G. (2008) Accessory Breast Tissue in Axilla Masquerading as Breast Cancer Recurrence. Journal of Cancer Research and Therapeutics, 4, 95-96. https://doi.org/10.4103/0973-1482.42258

[12] Berg, W.A., Campassi, C.I. and Iofe, O.B. (2003) Cystic Lesions of the Breast: Sonographic-Pathologic Correlation. Radiology, 227, 183-191.

https://doi.org/10.1148/radiol.2272020660 
[13] Taylor, D., Lazberger, J., Ives, A., Wylie, E. and Sauders, C. (2011) Reducing Delay in the Diagnosis of Pregnancy-Associated Breast Cancer; How Imaging Can Help Us. Journal of Medical Imaging and Radiation Oncology, 55, 33-42. https://doi.org/10.1111/j.1754-9485.2010.02227.x

[14] Ayyappan, A.P., Kulkarni, S. and Crystal. P. (2010) Pregnancy-Associated Breast Cancer: Spectrum of Imaging Appearances. The British Journal of Radiology, 83, 529-534. https://doi.org/10.1259/bjr/17982822

[15] Yu, J., Kim, M., Cho, H., et al. (2013) Breast Diseases during Pregnancy and Lactation. Obstetrics \& Gynecology Science, 56, 143-159. https://doi.org/10.5468/ogs.2013.56.3.143

[16] Bell, H., Lynch, A., Harle, R. and Peters, G. (2013) Breast Disorders during Pregnancy and Lactation: The Differential Diagnosis. Journal of Clinical Gynecology and Obstetrics, 2, 47-50.

[17] Henningsen, C., Kuntz, K. and Youngs, D. (2014) Breast Mass; Clinical Guide to Sonography: Exercises for Critical Thinking. 2nd Edition, Elsevier, St. Louis, 322-342.

[18] Strohl, L. (2011) Breast Sonography. In: Curry, R. and Tempkin, B., Eds., Sonography: Introduction to Normal Structure and Function, 3rd Edition, Elsevier, St. Louis, 456-469.

[19] John, S., Dialani, V., Marrotti, J. and Mehta, T.S. (2013) Breast Disease in the Pregnant and Lactating Patient: Radiological-Pathological Correlation. Insights into Imaging, 4, 527-538. https://doi.org/10.1007/s13244-012-0211-y 